\title{
Perioperative Management of Hilar Cholangiocarcinoma
}

\author{
Katherine E. Poruk ${ }^{1}$, Timothy M. Pawlik ${ }^{1}$, and Matthew J. Weiss ${ }^{1}$ \\ Matthew J. Weiss: mweiss5@jhmi.edu \\ ${ }^{1}$ Department of Surgery, The Johns Hopkins University School of Medicine, Halsted 614600 N. \\ Wolfe Street, Baltimore, MD 21287, USA
}

\begin{abstract}
Background-Cholangiocarcinoma is the most common primary tumor of the biliary tract although it accounts for only $2 \%$ of all human malignancies. We herein review hilar cholangiocarcinoma including its risk factors, the main classification systems for tumors, current surgical management of the disease, and the role chemotherapy and liver transplantation may play in selected patients.
\end{abstract}

Methods-We performed a comprehensive literature search using PubMed, Medline, and the Cochrane library for the period 1980-2015 using the following MeSH terms: "hilar cholangiocarcinoma", "biliary cancer", and "cholangiocarcinoma". Only recent studies that were published in English and in peer reviewed journals were included.

Findings-Hilar cholangiocarcinoma is a disease of advanced age with an unclear etiology, most frequently found in Southeast Asia and relatively rare in Western countries. The best chance of long-term survival and potential cure is surgical resection with negative surgical margins, but many patients are unresectable due to locally advanced or metastatic disease at diagnosis. As a result of recent efforts, new methods of management have been identified for these patients, including preoperative portal vein embolism and biliary drainage, neoadjuvant chemotherapy with subsequent transplantation, and chemoradiation therapy.

Conclusion-Current management of hilar cholangiocarcinoma depends on extent of the tumor at presentation and includes surgical resection, liver transplantation, portal vein embolization, and chemoradiation therapy. Our understanding of hilar cholangiocarcinoma has improved in recent years and further research offers hope to improve the outcome in patients with these rare tumors.

\section{Keywords}

Hilar cholangiocarcinoma; Biliary cancer

\section{Overview}

Cholangiocarcinoma is the most common primary tumor of the biliary tract although it accounts for only $2 \%$ of all human malignancies. ${ }^{1}$ Cholangiocarcinoma arises from the malignant growth of the epithelial lining of the biliary ducts and is classified into intrahepatic, perihilar, or distal subtypes based on its location. ${ }^{2}$ Hilar cholangiocarcinomas 
(HCs), or tumors which develop from the right and/or left hepatic ducts at or near the biliary confluence, are the most common type and account for up to $70 \%$ of all cases. ${ }^{3-7}$ Commonly referred to as Klatskin tumors after the description by Dr. Gerald Klatskin in 1965, HCs are difficult to diagnose due to the often silent clinical nature. ${ }^{8}$ The best chance of long-term survival and potential cure is surgical resection with negative surgical margins, but many patients are unresectable due to locally advanced or metastatic disease at diagnosis. ${ }^{9}{ }^{910}$ Research has demonstrated a survival benefit in properly-selected patients who undergo neoadjuvant chemotherapy followed by liver transplantation. Preoperative management with a combination of portal vein embolization and preoperative biliary drainage may help reduce postoperative complications in selected patients, and chemotherapy and radiation may have utility in prolonging survival after resection. We herein review HC including its risk factors, the main classification systems for tumors, current surgical management of the disease, and the role chemotherapy and liver transplantation may play in selected patients. We performed a comprehensive literature search using PubMed, Medline, and the Cochrane library for the period 1980-2015 using the following MeSH terms: "hilar cholangiocarcinoma," "biliary cancer," and "cholangiocarcinoma." These terms were restricted to the title, abstract, and keywords. We included only recent studies that were published in English and in peer reviewed journals.

\section{Demographics}

$\mathrm{HC}$ is a disease of advanced age typically presenting in patients beyond the sixth decade of life. ${ }^{2}$ Two large studies each including over 200 patients with $\mathrm{HC}$ demonstrated a median age at diagnosis of 65 and 68 years, respectively, with a peak age of diagnosis in the eighth decade of life. ${ }^{7,9}$ Men and women are affected in roughly equal proportions, although several studies have demonstrated a slightly higher incidence in males. ${ }^{7,11}$ Globally, the highest prevalence of $\mathrm{HC}$ is in Southeast Asia, with the disease relatively uncommon in the USA. ${ }^{12}$ While the majority of patients with $\mathrm{HC}$ who present for surgical resection in Western countries are Caucasian, no clear differences in the incidence of cholangiocarcinoma among different ethnicities have been described. ${ }^{7}$

The etiology of $\mathrm{HC}$ is unclear, especially in Western countries, but several risk factors have been identified. Infection appears to be strongly linked to the development of cholangiocarcinoma, especially in Asian countries. ${ }^{13}$ Liver flukes, including Chlonorchis sinensis and Opisthorchis viverrini, can chronically infect the bile ducts and lead to the development of cholangiocarcinoma, with a reported relative risk of 4.8 (95\% confidence interval (CI) 2.8-8.4). ${ }^{13-16}$ A meta-analysis of published data has demonstrated a strong association between the hepatitis $\mathrm{B}$ and hepatitis $\mathrm{C}$ viruses with the development of cholangiocarcinoma, with a relative risk of 2.6 (95\% CI 1.5-4.6) and 1.8 (95 \% CI 1.4-2.4), respectively. ${ }^{13,15,17,18}$ Other risk factors that have been associated with $\mathrm{HC}$ include heavy alcohol consumption, primary sclerosing cholangitis, chronic pancreatitis, cholelithiasis, and choledochal cysts. ${ }^{15,16,18}$ However, it has been noted that the majority of patients diagnosed with $\mathrm{HC}$ in Western countries do not have a recognized risk factor. ${ }^{19}$

Primary sclerosing cholangitis (PSC), an autoimmune disease leading to inflammation and multifocal stricturing of the intrahepatic and extrahepatic bile ducts, has been associated 
with an increased incidence of all types of cholangiocarcinoma. In a cohort of 305 Swedish patients with PSC, $8 \%$ went on to develop cholangiocarcinoma over a median follow-up time of 5 years. ${ }^{20}$ Similar studies demonstrated an incidence of cholangiocarcinoma of $13.2 \%$ in a cohort of 273 German PSC patients followed for a median of 6.3 years and $6.8 \%$ in 161 PSC patients followed for 11.5 years. ${ }^{21,22}$ Furthermore, occult cholangiocarcinoma has been identified in up to $40 \%$ of PSC patients at autopsy and between 9 and $36 \%$ of liver explants after transplantation. ${ }^{23-26}$ The highest risk of cholangiocarcinoma has been shown within the first year after diagnosis of PSC, and careful screening and regular follow-up are recommended for patients who present with PSC for at least the first 2 years following diagnosis. ${ }^{24,27} \mathrm{~A}$ strong relationship with PSC and ulcerating colitis has also been described, and an association between ulcerative colitis and $\mathrm{HC}$ has also been suggested with diagnosis at a younger age than in sporadic cases. ${ }^{27,28}$

\section{Histology and Tumor Characteristics}

The majority of $\mathrm{HC}$ cases occur sporadically, and the precise etiology of the disease is unknown. However, chronic inflammation and stasis of bile flow are felt to be the key contributors to genetic alterations in biliary cells leading to malignancy. Specific genetic mutations have been identified in $\mathrm{HCs}$, including $\mathrm{K}$-ras, $\mathrm{C}$-myc, $p 53$, and $\mathrm{Bcl}-2$, helping to understand the mechanisms that lead to malignant transformation of the biliary tract. ${ }^{29} \mathrm{~A}$ recent study reported $94 \%$ of resected tumors stained positively for the tumor suppressor gene $p 53$, although others have suggested a lower rate of mutations in this gene. ${ }^{30-32}$ Other studies have reported mutations in the $K$-ras gene in up to $60 \%$ of patients, similar to those found in other gastrointestinal cancers; K-ras mutations were noted to be particularly common in hilar tumors larger than $3 \mathrm{~cm} .{ }^{33,34} \mathrm{~K}$-ras mutations have also been noted to be found more frequent in patients with lymph node metastases than those without, and are associated with poor survival. ${ }^{35}$ Other genes commonly mutated include $E r b B-2, B R A F$, $B c 1-2, D P C 4 / S m a d 4$, and E-cadherin, although the specific mutations seen in an individual case of $\mathrm{HC}$ differ drastically amongst patients. ${ }^{29,36}$

Based upon the histological appearance of the tumor, $\mathrm{HCs}$ can be further classified into three distinct subtypes: sclerosing, nodular, and papillary. ${ }^{37,38}$ Sclerosing tumors are the most common type, comprising up to $70 \%$ of all cholangiocarcinomas, and are frequently found at the liver hilum. ${ }^{27}$ These tumors are firm and cause annular thickening of the bile duct, often with longitudinal and radial tumor infiltration. ${ }^{37}$ In addition, sclerosing tumors can locally invade surrounding tissues, especially periductal neural tissue and vessels, resulting in associated fibrosis and inflammation of periductal tissues. ${ }^{27}$ Nodular cholangiocarcinomas are firm, irregular nodules of tumor that project into the lumen of the duct. In some cases, tumors may have features of both types and are classified as "nodularsclerosing." Papillary tumors, the rarest subtype, are soft and friable and are often characterized by a polypoid mass that expands rather than contracts the duct. ${ }^{37}$ Papillary HCs often arise from a well-defined stalk allowing for a mobile tumor inside the bile duct. ${ }^{38}$ These tumors are more commonly found in the distal bile duct and only rarely at the hilum. As papillary tumors are less likely to invade adjacent structures, these tumors have a more favorable prognosis compared to the more common subtypes. 


\section{Classification}

Classification of perihilar cholangiocarcinoma has focused on differentiating the tumor from intrahepatic and extrahepatic subtypes but also stratifying tumors based on specific anatomic and prognostic factors. In 1975, Bismuth and Corlette published one of the first anatomical classification systems for perihilar cholangiocarcinomas, with additional modifications described in 1992. ${ }^{39,40}$ This classification system organized lesions into four subtypes based upon tumor location and the extent of ductal infiltration to guide surgical management. Type I perihilar cholangiocarcinomas are those limited to the common hepatic duct immediately below the level of the bifurcation, while type II lesions involve the confluence of the left and right hepatic ducts but not beyond. Type III tumors are type II perihilar cholangiocarcinomas with extension of the tumor into the hepatic ducts; type IIIa involve extension into the right hepatic duct while type IIIb tumors extent into the left hepatic duct. Type IV lesions have extension of a tumor to the bifurcations of both the right and left hepatic ducts or have multifocal involvement. Recommendations for the type and extent of surgical resection were made based on the subtype, ranging from local excision for type I lesions to hepatectomy and liver transplantation for type IV tumors. ${ }^{40}$ While this classification system is useful for stratifying patients based on biliary involvement of the tumor, it is limited in its ability to predict resectability and survival given the absence of information regarding vascular encasement, lymph node metastases, and hepatic atrophy.

Other staging systems have been proposed based upon published prognostic factors and resectability criteria in addition to anatomic tumor location. One of the most commonly used is the American Joint Committee on Cancer (AJCC) tumor-node-metastasis (TNM) staging system, which takes into account the size and extent of the primary tumor, regional lymph nodes, and distant metastases. ${ }^{41}$ While this staging system is useful in determining resectability of a tumor, the accuracy of the AJCC staging system with regards to predicting survival has been questioned. ${ }^{42,43}$ The Memorial Sloan-Kettering Cancer Center (MSKCC) staging system put forth by Blumgart and colleagues attempted to expand on the BismuthCorlette classification by stratifying patients into one of three T stages. ${ }^{9}$ This system classifies a tumor according to its location and extent of bile duct involvement in addition to the presence of portal venous invasion and associated hepatic lobar atrophy. ${ }^{9}$ Increasing T stage was found to be associated with worse survival in the 219 patients analyzed $(P<0.01)$ in addition to the decreased likelihood of resectability and achieving a negative (R0) resection margin $(P<0.01) .{ }^{9}$ In a novel cohort of 380 patients, this staging system was found to predict accurately resectability and $\mathrm{R} 0$ resection margin. ${ }^{44}$ However, this study was limited by the low proportion of patients included ( 80 of 219) who were ultimately found to be resectable at the time of surgery in addition to a reported lack of a reproducible survival benefit in a novel patient cohort. ${ }^{42}$ Regardless of the limitations, it highlights an important need for stratifying patients at the time of resection by incorporating known important prognostic factors.

\section{Diagnosis and Workup}

The diagnosis of $\mathrm{HC}$ remains difficult, as most patients are asymptomatic until the disease has advanced and spread beyond the biliary tree. Clinical presentation depends on tumor size 
and location. The most common symptom of $\mathrm{HC}$ is jaundice and is present in up to $90 \%$ of patients; however, this often does not develop until the tumor has grown large enough to obstruct the biliary tree. ${ }^{4,7}$ Other common symptoms include fatigue, weight loss, pruritus, and abdominal pain but are relatively nonspecific, and as a result, are frequently not associated with an underlying diagnosis of malignancy. ${ }^{4,7}$ Additionally, some patients will be diagnosed based upon abnormalities noted on routine blood tests, with elevated serum alkaline phosphatase and bilirubin levels the most often seen laboratory anomalies in patients with $\mathrm{HC} .{ }^{45}$ In general, physicians should have a high clinical index of suspicion to diagnose $\mathrm{HC}$ in patients who present with these nonspecific signs and symptoms.

In a patient who presents with a strong suspicion for $\mathrm{HC}$ or an abnormality found on imaging, a thorough evaluation is recommended. The most recent guidelines from the National Comprehensive Cancer Network (NCCN) for an extrahepatic cholangiocarcinoma recommend abdominal imaging by computed tomography (CT) or magnetic resonance imaging (MRI) to assess for vascular invasion and provide noninvasive cholangiography, chest CT to rule out metastatic disease, and laboratory testing including liver function tests (LFTs) in addition to cancer markers such as carbohydrate antigen 19-9 (CA19-9) and carcinoembryonic antigen (CEA). ${ }^{46}$ The sensitivity and specificity of CA19-9 for differentiating benign from malignant biliary strictures are 76 and $92 \%$, respectively. ${ }^{47}$ The reported sensitivity and specificity of CEA vary widely for $\mathrm{HC}$ and has been reported between 33-84 \% and 33-100 \%, respectively. ${ }^{48,49}$ Thus, while an elevated serum CA19-9 or CEA may help confirm the diagnosis of $\mathrm{HC}$, a normal value cannot definitively rule out the disease. In addition, CA19-9 and CEA levels have been shown to correlate with resectability, tumor stage, and overall survival and provide more utility as prognostic biomarkers than for diagnostic workup. ${ }^{50}$

Cross-sectional imaging is essential for the diagnosis and operative planning of HC. Often times, $\mathrm{HC}$ is first diagnosed after patients with abdominal pain or other nonspecific symptoms that is evaluated by imaging. High quality cross-sectional imaging utilizing multidetector contrast enhanced helical computed tomography (MDCT) or magnetic resonance cholangiopancreatography (MRCP) is recommended to workup and assess patients with a suspected HC (Fig. 1). The most frequently obtained imaging is MDCT given its widespread availability in most clinics and is notable for an overall accuracy of 60-90\% in determining resectability of a tumor. ${ }^{51-55}$ Notably, MDCT has a reported accuracy of $96 \%$ for determining portal vein invasion, $93 \%$ for hepatic artery invasion, and $96 \%$ for determining longitudinal tumor extension using the Bismuth-Corlette classification. ${ }^{55}$ However, the accuracy of MDCT for determining nodal or peritoneal metastases is significantly lower. ${ }^{54,56}$ Most importantly, cross-sectional imaging is recommended before the placement of biliary stents to allow for a more complete assessment of the primary lesion.

MRI and MRCP have been increasingly used for $\mathrm{HC}$ as it allows for easier identification of the tumor's extent for staging purposes and better visualization of the biliary tree allowing for more complete surgical planning. ${ }^{57} \mathrm{MRI}$ is also better suited to investigate the various types of soft tissue components, including bile ducts, blood vessels, and invasion into nearby liver parenchyma. Cholangiocarcinomas can often be identified due to thickening and 
irregularity of the bile duct walls with upstream dilatation of the intrahepatic bile ducts. ${ }^{57,58}$ By MRI, HCs appear mildly to moderately hypointense, especially compared to nearby liver parenchyma, on T1-weighted images and isointense to mildly hyperintense on T2-weighted images. ${ }^{58}$ The sensitivity of MRI for detecting a HC is reported to be $90 \%$ and may be higher than MDCT alone. ${ }^{59}$ In addition, studies have shown MRCP to be equivalent to endoscopic retrograde cholangiopancreatography (ERCP) in the diagnosis of $\mathrm{HC}$, and invasive cholangiography has been largely abandoned as a diagnostic tool in favor of MRCP or other non-invasive imaging modalities. ${ }^{60-62}$

If preoperative decompression or tissue biopsies are necessary, ERCP or percutaneous biliary transhepatic cholangiography (PTC) and drainage (PBD) are useful in evaluating the location of the tumor while allowing for decompression and drainage of any obstruction (Fig. 2). ERCP and PTC have been shown to have a similar sensitivity and specificity (75$85 \%$ and $70-75 \%$, respectively) for the ability to obtain a tissue diagnosis, although a negative biopsy does not rule out HC. ${ }^{63,64}$ Given similar diagnostic abilities, either ERCP or PTC is an acceptable choice for workup and is often institutionally dependent. Endoscopic ultrasound (EUS) with fine needle aspiration (FNA) has also been used in HC patients to biopsy the primary tumor and regional lymph nodes. ${ }^{65}$ Endoscopic ultrasound guided FNA has a reported accuracy as high as $91 \%$ and can detect metastatic lymph nodes in up to $20 \%$ of patients with negative abdominal imaging. ${ }^{65-68}$ However, transperitoneal FNA has been associated with a higher rate of peritoneal metastases in some studies, and as a result, should be avoided unless non-surgical therapy is considered. ${ }^{69}$

\section{Preoperative Management}

Management of biliary obstruction in patients with overt jaundice may be required prior to surgical resection to relieve symptoms and reduce the risk of perioperative morbidity. Hepatic resection in the setting of jaundice and significant biliary obstruction has been associated with an increased risk of postoperative complications, increasing the need for preoperative management. ${ }^{70,71}$ While routine percutaneous biliary drainage in all patients with $\mathrm{HC}$ is not advocated given a risk of procedure-related adverse events, drainage is selected if patients are recommended to reduce the risk of operative complications. ${ }^{72}$ Studies have demonstrated that percutaneous drainage in patients with jaundice and hyperbilirubinemia can decrease postoperative complications but has not been shown to provide decreased operative mortality or improved overall survival. ${ }^{62,73-75}$ Currently, the optimal serum bilirubin level for surgery has not been determined, nor is the optimal duration of PBD known in HC. Biliary drainage should be reserved for selected patients with clinically evident jaundice or significant biliary obstruction prior to surgery.

Portal vein embolization (PVE) should be considered preoperatively for patients in whom the functional liver remnant (FLR) is estimated to be less than 20-30\% of the total liver volume after major liver resection. ${ }^{76-79}$ PVE is typically performed by a percutaneous transhepatic approach with insertion of a catheter into the portal system with subsequent injection of embolic materials into the desired venous branches to occlude flow; typical embolization materials include fibrin glue, polidocanol-foam, gelatin sponge, metallic coils, or cyanoacrylate. ${ }^{79} \mathrm{PVE}$ is primarily reserved for patients undergoing a right or extended 
right hepatectomy, as the left lateral section and caudate lobe are more likely to have inadequate FLR volumes after resection compared with the right hemiliver. One large systematic review reported at least $91.6 \%$ of all PVE patients underwent embolization of either segments $5-8$ or segments $4-8 .{ }^{79}$ PVE has been shown to increase FLR volumes in those patients with normal liver parenchyma prior to major hepatic resection for hepatic malignancy, although a majority of patients with chronic liver disease have also been shown to obtain significant benefit. ${ }^{76}$ Postoperative morbidity and mortality for patients undergoing preoperative PVE are comparable to patients with adequate FLR volumes, and long-term median survival is equivalent between groups undergoing hepatectomy for a hepatic malignancy. ${ }^{76,77}$ Additionally, patients with decreased FLR volumes who do not undergo PVR have been shown to have a higher incidence of postoperative liver failure than PVE patients. ${ }^{78}$ Patients with chronic liver disease may particularly benefit from PVE, as such patients with marginal FLR who undergo preoperative PVR seem to have a decreased incidence of postoperative complications and shorter hospital stay after hepatectomy. ${ }^{76}$ Surgeons should strongly consider PVE in patients with concern for inadequate remnant liver volumes after hepatectomy for cholangiocarcinoma.

\section{Surgical Management}

Surgical resection is the best chance of long-term survival and cure in patients with HC. ${ }^{80}$ However, resection of HC presents challenges when compared to intrahepatic and distal cholangiocarcinomas, which can often be treated with hepatectomy or pancreaticoduodenectomy, respectively. ${ }^{27}$ Based on the location and subtype of $\mathrm{HC}$, recommended surgical treatment can involve local excision, hepatectomy, or even liver transplantation. ${ }^{40}$ Furthermore, many patients will present with advanced disease determined to be unresectable at the time of diagnosis given the tendency of tumors to spread by direct extension into nearby blood vessels and organs. Current criteria for unresectable disease include main portal vein involvement or encasement, bilateral spread to secondary biliary radicles, bilateral involvement of hepatic artery and/or portal venous branches, unilateral hepatic artery involvement with contralateral ductal spread, and the presence of metastases to distant lymph nodes or organs. ${ }^{81}$ However, even for patients who do not have these factors on preoperative imaging, as many as $40 \%$ of patients will be found unresectable at the time of exploration. ${ }^{10}$ In the MSKCC experience, $29 \%$ of $\mathrm{HC}$ patients at initial presentation had metastatic or locally advanced disease making them ineligible for surgical resection; of the 160 patients who progressed to exploration, 80 had findings that precluded resection. ${ }^{9}$ Given the high percentage of patients found to be unresectable at exploration, some surgeons have advocated exploratory laparoscopy for all patients with $\mathrm{HC}$, but the utility of its routine use is mixed. ${ }^{82-84}$

For patients with operable tumors, surgery remains the primary treatment method at this time. Numerous studies have shown significantly longer survival in patients who undergo resection compared with those that are not surgical candidates, and overall 5-year survival after surgery approaches $53 \%$ in highly selected patients (Table 1). ${ }^{10,85-89}$ Table 1 provides the reported overall 5-year survival for all studies published since 2010 which included over 100 patients, in order to limit any potential biases in smaller studies. In general, the standard therapy for $\mathrm{HC}$ is major hepatectomy combined with extrahepatic biliary tree resection and 
lymphadenectomy. ${ }^{9,90-92}$ Left hepatectomy is required for Bismuth-Corlette IIIb lesions, while Bismuth-Corlette I, II, and IIIa lesions will usually require an extended right hepatectomy. In addition, simultaneous caudate lobe resection is highly recommended given its association with improved long-term survival and decreased local recurrence rates. ${ }^{93-95}$ For advanced $\mathrm{HC}$ with vascular involvement, concomitant vascular resection has been advocated by some surgeons. However, data regarding concurrent portal vein resection (PVR) is mixed. One meta-analysis recently demonstrated no difference in morbidity, R0 resection rates, or 5-year survival after hepatectomy with or without PVR. ${ }^{96}$ While PVR was associated with higher postoperative death rates, this relationship was not seen in a subgroup analysis of patients treated at experienced centers. Conversely, a large multi-institutional analysis of 305 patients treated at high volume, experienced centers demonstrated significantly increased 90-day mortality among patients who underwent PVR with hepatectomy. ${ }^{97}$ In this study, 5-year survival was not significantly different for patients after hepatectomy with or without PVR (28.2 vs. $33.2 \%$ ), and a survival benefit was seen in patients with an R0 resection margin. Thus, in high-volume centers with experienced surgeons, hepatectomy with PVR has a noted survival benefit in patients and should not be avoided when it would lead to an R0 resection. Alternatively, hepatic artery reconstruction is associated with significantly increased morbidity and mortality without a notable survival benefit and is not routinely used in the treatment for $\mathrm{HC}$ in Western countries. ${ }^{98,99}$

The goal of resection for $\mathrm{HC}$ is to achieve a negative, or $\mathrm{R} 0$, surgical margin in order to improve long-term survival. Multiple studies have demonstrated that overall survival is significantly increased when R0 surgical margins are obtained in comparison to an R1 resection, where microscopic disease is present at the operative margin. ${ }^{7,44}$ One of the largest series including $380 \mathrm{HC}$ patients from Memorial Sloan-Kettering Cancer Center demonstrated a significantly longer median disease-specific survival after an R0 resection compared with an R1 resection (43.5 vs. 23.1 months, respectively; $P<0.001)$ (Fig. 3). ${ }^{44} \mathrm{An}$ analysis of 281 perihilar cholangiocarcinoma patients at the Johns Hopkins Hospital also demonstrated significantly increased survival for patients who underwent an R0 resection. ${ }^{7}$ A multi-institutional study of 305 patients who underwent extrahepatic biliary duct resection, hepatectomy, or hepatectomy with PVR demonstrated significantly improved survival for patients with an R0 resection margin, despite the operative method. ${ }^{97}$ In addition to surgical margin, several other operative factors and tumor characteristics have been associated with prolonged survival after surgical resection. The presence of nodal metastases has been shown in several studies to be associated with worse survival by multivariate analysis. ${ }^{97,100,101}$ Smaller case analyses have also shown worse survival after resection in patients with elevated preoperative serum bilirubin, histologic tumor type, and tumor differentiation, although these findings vary based on the study. ${ }^{100,102,103}$

\section{Liver Transplantation}

Liver transplantation has emerged as a potential treatment option in patients for which the tumor is unresectable or an R0 resection margin cannot be achieved. Historically, liver transplantation for cholangiocarcinoma was associated with poor long-term survival, and 5year survival rates were below than $30 \%$ at many centers. ${ }^{104,105}$ These survival rates were poor compared to transplantation for other liver diseases, and therefore, cholangiocarcinoma 
was considered by many to be a contraindication to transplant. However, the majority of patients in these early studies had advanced disease and did not receive neoadjuvant chemotherapy. More recent studies have evaluated liver transplantation in carefully selected patients after neoadjuvant chemotherapy, and improvements in survival rates have been demonstrated. The predominant protocol involves treatment with chemotherapy and radiation for patients with localized, non-metastatic perihilar cholangiocarcinoma without intrahepatic disease. If a donor is identified after treatment, the patient will undergo staging laparoscopy and, if negative, will proceed to liver transplantation. ${ }^{106,107}$ At the Mayo clinic, 120 patients with cholangiocarcinoma treated by this protocol and subsequent liver transplantation resulted in a 5-year overall survival of $73 \%$, drastically higher than traditional outcomes for resection. ${ }^{106}$ One smaller study of 24 patients with unresectable perihilar cholangiocarcinoma without extrahepatic metastases who underwent liver transplantation after preoperative chemoradiation therapy had a 5-year survival of $82 \% .^{107}$ In addition, multiple studies have demonstrated that patients with PSC-associated cholangiocarcinoma have better outcomes and survival with transplantation than resection alone. ${ }^{108,109}$ It is important to note, however, that patients undergoing transplantation were highly selected and were required to pass a stringent inclusion criteria, making it difficult to generalize the results to all patients with HC. Beyond patients with PSC, treatment should be tailored to the individual patient in order to provide the best opportunity for prolonged survival, whether that treatment involves resection or transplantation.

\section{Medical Management}

\section{Chemotherapy}

Medical management of $\mathrm{HC}$ with chemotherapy and radiation alone leads to a poor outcomes when compared with complete surgical resection. ${ }^{110}$ As a result, chemotherapy is often limited to patients (1) with unresectable disease as sole therapy, (2) prior to potential transplantation, or (3) as adjuvant therapy for worrisome features after resection such as a positive resection margin or nodal metastases. Most major studies regarding chemotherapeutic regimens for cholangiocarcinoma are limited due to small numbers and inclusion of patients with different malignancies of the biliary tract, including gallbladder cancers. However, the majority of studies have demonstrated the superiority of combination therapies with more than one agent compared with single-agent treatment. ${ }^{10,111}$ Early studies involved treatment with 5-fluorouracil (5-FU), which in combination with other agents such as Adriamycin, mitomycin $\mathrm{C}$, and cisplatin offered a median survival between 5 and 12 months. ${ }^{110,112-114}$ However, response rates with 5-FU are under $40 \%$, leading to the evaluation of other chemotherapeutic agents. Current regimens for $\mathrm{HC}$ primarily include gemcitabine, with objective response rates between 8 and $60 \%$ for gemcitabine-alone and a median overall survival of 6.3 to 16.0 months. ${ }^{115}$ Randomized control trials of gemcitabine in combination with other chemotherapeutic agents for the treatment of advanced biliary cancers have shown improvement in time-to-progression and progression-free survival. ${ }^{111}$ Retrospective reviews have also demonstrated prolonged overall survival in patients who received adjuvant gemcitabine-based chemotherapy after surgical resection compared to those undergoing surgery alone. ${ }^{116}$ Recent attempts have also been made to treat patients with agents targeted to specific genes such as EGFR and VEGFR, but early clinical trials 
involving these agents have failed to show any benefit. ${ }^{11-119}$ Further prospective clinical evaluation is needed regarding chemotherapy for $\mathrm{HC}$; particularly, the role neoadjuvant chemotherapy may play in downsizing tumors prior to resection.

\section{Radiation Therapy}

Radiation therapy has similarly been utilized postoperatively for the treatment of $\mathrm{HC}$ and is often given concurrently with adjuvant chemotherapy. However, the data have been mixed regarding outcomes. An early prospective trial of radiation therapy both in the adjuvant setting after resection and as palliative therapy for unresectable disease demonstrated no survival benefit compared to patients who did not undergo radiation. ${ }^{120}$ Moreover, only resection was noted to be a significant prognostic factor when accounting for other variables, continuing to support surgery as the mainstay of treatment for HC. Small retrospective reviews comparing adjuvant radiation therapy to surgery alone have been mixed, with a survival benefit seen in some but not others. ${ }^{121-123}$ A retrospective analysis of 63 patients demonstrated improved prognosis in patients with microscopically positive resection margins who underwent adjuvant radiation therapy as opposed to surgery alone. ${ }^{123}$ In addition, the best survival was noted among patients who underwent combined intraoperative and postoperative radiation therapy. The SWOG S0809 prospective phase II trial is currently enrolling patients to evaluate for a survival benefit in patients treated with gemcitabine/capecitabine chemotherapy and radiation therapy after surgical resection. This study should help to further clarify that the role radiation therapy may have as an adjunct to surgery, especially in patients with positive resection margins. In addition, as with chemotherapy, there is limited data on the use of neoadjuvant radiation therapy for $\mathrm{HC}$, and further prospective study is necessary to determine any potential survival benefit.

\section{Conclusion}

$\mathrm{HC}$ is a rare primary tumor of the biliary tract which occurs at or near the biliary confluence. ${ }^{1}$ These tumors are difficult to diagnose due to a silent clinical nature and limited early detection modalities, contributing to an overall poor survival for patients with this disease. Treatment with major hepatectomy combined with extrahepatic biliary tree resection and lymphadenectomy offers the best chance of long-term survival and potential cure, although this treatment is limited to patients with resectable disease without metastases at the time of diagnosis. ${ }^{9}, 10$ Recent studies at specialized, high-volume centers have demonstrated a survival benefit in patients who undergo neoadjuvant chemotherapy and liver transplantation, offering a new treatment modality for patients with unresectable tumors.

Adjuvant chemotherapy and radiation appear to offer a survival benefit in selected patients, especially those with R1 resection margins, and current clinical trials hope to further determine the optimal patient population and treatment regimen for HC. Our understanding of $\mathrm{HC}$ has improved in recent years and further research offers hope to improve the outcome in patients with these rare tumors.

\section{References}

1. Bragazzi MC, C V, Carpino G, Venere R, Semeraro R, Gentile R, Gaudio E, Alvaro D. Cholangiocarcinoma: Epidemiology and risk factors. Transl Gastrointest Cancer. 2012; 1:21-32. 
2. Everhart JE, Ruhl CE. Burden of digestive diseases in the United States Part III: Liver, biliary tract, and pancreas. Gastroenterology. 2009; 136(4):1134-44. [PubMed: 19245868]

3. Burke EC, Jarnagin WR, Hochwald SN, et al. Hilar Cholangiocarcinoma: patterns of spread, the importance of hepatic resection for curative operation, and a presurgical clinical staging system. Ann Surg. 1998; 228(3):385-94. [PubMed: 9742921]

4. Launois B, Reding R, Lebeau G, et al. Surgery for hilar cholangiocarcinoma: French experience in a collective survey of 552 extrahepatic bile duct cancers. J Hepatobiliary Pancreat Surg. 2000; 7(2): 128-34. [PubMed: 10982604]

5. Nakeeb A, Pitt HA, Sohn TA, et al. Cholangiocarcinoma. A spectrum of intrahepatic, perihilar, and distal tumors. Ann Surg. 1996; 224(4):463-73. discussion 473-5. [PubMed: 8857851]

6. Welzel TM, McGlynn KA, Hsing AW, et al. Impact of classification of hilar cholangiocarcinomas (Klatskin tumors) on the incidence of intra- and extrahepatic cholangiocarcinoma in the United States. J Natl Cancer Inst. 2006; 98(12):873-5. [PubMed: 16788161]

7. DeOliveira ML, Cunningham SC, Cameron JL, et al. Cholangiocarcinoma: thirty-one-year experience with 564 patients at a single institution. Ann Surg. 2007; 245(5):755-62. [PubMed: 17457168]

8. Klatskin G. Adenocarcinoma of the Hepatic Duct at Its Bifurcation within the Porta Hepatis. An Unusual Tumor with Distinctive Clinical and Pathological Features. Am J Med. 1965; 38:241-56. [PubMed: 14256720]

9. Jarnagin WR, Fong Y, DeMatteo RP, et al. Staging, resectability, and outcome in 225 patients with hilar cholangiocarcinoma. Ann Surg. 2001; 234(4):507-17. discussion 517-9. [PubMed: 11573044]

10. Cho MS, Kim SH, Park SW, et al. Surgical outcomes and predicting factors of curative resection in patients with hilar cholangiocarcinoma: 10-year single-institution experience. J Gastrointest Surg. 2012; 16(9):1672-9. [PubMed: 22798185]

11. Suarez-Munoz MA, Fernandez-Aguilar JL, Sanchez-Perez B, et al. Risk factors and classifications of hilar cholangiocarcinoma. World J Gastrointest Oncol. 2013; 5(7):132-8. [PubMed: 23919107]

12. Khan SA, Toledano MB, Taylor-Robinson SD. Epidemiology, risk factors, and pathogenesis of cholangiocarcinoma. HPB (Oxford). 2008; 10(2):77-82. [PubMed: 18773060]

13. Shin HR, Oh JK, Masuyer E, et al. Epidemiology of cholangiocarcinoma: an update focusing on risk factors. Cancer Sci. 2010; 101(3):579-85. [PubMed: 20085587]

14. Choi D, Lim JH, Lee KT, et al. Cholangiocarcinoma and Clonorchis sinensis infection: a casecontrol study in Korea. J Hepatol. 2006; 44(6):1066-73. [PubMed: 16480786]

15. Lee TY, Lee SS, Jung SW, et al. Hepatitis B virus infection and intrahepatic cholangiocarcinoma in Korea: a case-control study. Am J Gastroenterol. 2008; 103(7):1716-20. [PubMed: 18557716]

16. Honjo S, Srivatanakul P, Sriplung H, et al. Genetic and environmental determinants of risk for cholangiocarcinoma via Opisthorchis viverrini in a densely infested area in Nakhon Phanom, northeast Thailand. Int J Cancer. 2005; 117(5):854-60. [PubMed: 15957169]

17. El-Serag HB, Engels EA, Landgren O, et al. Risk of hepatobiliary and pancreatic cancers after hepatitis C virus infection: a population-based study of U.S. veterans. Hepatology. 2009; 49(1): 116-23. [PubMed: 19085911]

18. Shaib YH, El-Serag HB, Nooka AK, et al. Risk factors for intrahepatic and extrahepatic cholangiocarcinoma: a hospital-based case-control study. Am J Gastroenterol. 2007; 102(5):101621. [PubMed: 17324130]

19. Ben-Menachem T. Risk factors for cholangiocarcinoma. Eur J Gastroenterol Hepatol. 2007; 19(8): 615-7. [PubMed: 17625428]

20. Broome U, Olsson R, Loof L, et al. Natural history and prognostic factors in 305 Swedish patients with primary sclerosing cholangitis. Gut. 1996; 38(4):610-5. [PubMed: 8707097]

21. Tischendorf JJ, Hecker H, Kruger M, et al. Characterization, outcome, and prognosis in 273 patients with primary sclerosing cholangitis: a single center study. Am J Gastroenterol. 2007; 102(1):107-14. [PubMed: 17037993]

22. Burak K, Angulo P, Pasha TM, et al. Incidence and risk factors for cholangiocarcinoma in primary sclerosing cholangitis. Am J Gastroenterol. 2004; 99(3):523-6. [PubMed: 15056096]

23. Rosen CB, Nagorney DM, Wiesner RH, et al. Cholangiocarcinoma complicating primary sclerosing cholangitis. Ann Surg. 1991; 213(1):21-5. [PubMed: 1845927] 
24. Boberg KM, Bergquist A, Mitchell S, et al. Cholangiocarcinoma in primary sclerosing cholangitis: risk factors and clinical presentation. Scand J Gastroenterol. 2002; 37(10):1205-11. [PubMed: 12408527]

25. Goss JA, Shackleton CR, Farmer DG, et al. Orthotopic liver transplantation for primary sclerosing cholangitis. A 12-year single center experience. Ann Surg. 1997; 225(5):472-81. discussion 481-3. [PubMed: 9193175]

26. Chazouilleres O. Primary sclerosing cholangitis and biliary malignancy: a glimmer of hope? J Hepatol. 2004; 40(5):857-9. [PubMed: 15094236]

27. Kuang D, Wang GP. Hilar cholangiocarcinoma: pathology and tumor biology. Front Med China. 2010; 4(4):371-7. [PubMed: 21110142]

28. Altaee MY, Johnson PJ, Farrant JM, et al. Etiologic and clinical characteristics of peripheral and hilar cholangiocarcinoma. Cancer. 1991; 68(9):2051-5. [PubMed: 1717133]

29. Maroni L, Pierantonelli I, Banales JM, et al. The significance of genetics for cholangiocarcinoma development. Ann Transl Med. 2013; 1(3):28. [PubMed: 25332972]

30. Batheja N, Suriawinata A, Saxena R, et al. Expression of p53 and PCNA in cholangiocarcinoma and primary sclerosing cholangitis. Mod Pathol. 2000; 13(12):1265-8. [PubMed: 11144921]

31. Tullo A, D'Erchia AM, Honda K, et al. New p53 mutations in hilar cholangiocarcinoma. Eur J Clin Invest. 2000; 30(9):798-803. [PubMed: 10998080]

32. Tannapfel A, Sommerer F, Benicke M, et al. Mutations of the BRAF gene in cholangiocarcinoma but not in hepatocellular carcinoma. Gut. 2003; 52(5):706-12. [PubMed: 12692057]

33. Tada M, Omata M, Ohto M. High incidence of ras gene mutation in intrahepatic cholangiocarcinoma. Cancer. 1992; 69(5):1115-8. [PubMed: 1739910]

34. Ohashi K, Tstsumi M, Nakajima Y, et al. Ki-ras point mutations and proliferation activity in biliary tract carcinomas. Br J Cancer. 1996; 74(6):930-5. [PubMed: 8826860]

35. Isa T, Tomita S, Nakachi A, et al. Analysis of microsatellite instability, K-ras gene mutation and p53 protein overexpression in intrahepatic cholangiocarcinoma. Hepatogastroenterology. 2002; 49(45):604-8. [PubMed: 12063950]

36. Blechacz B, Gores GJ. Cholangiocarcinoma: advances in pathogenesis, diagnosis, and treatment. Hepatology. 2008; 48(1):308-21. [PubMed: 18536057]

37. Weinbren K, Mutum SS. Pathological aspects of cholangiocarcinoma. J Pathol. 1983; 139(2):21738. [PubMed: 6298394]

38. Jarnagin W, Winston C. Hilar cholangiocarcinoma: diagnosis and staging. HPB (Oxford). 2005; 7(4):244-51. [PubMed: 18333200]

39. Bismuth $\mathrm{H}$, Corlette MB. Intrahepatic cholangioenteric anastomosis in carcinoma of the hilus of the liver. Surg Gynecol Obstet. 1975; 140(2):170-8. [PubMed: 1079096]

40. Bismuth H, Nakache R, Diamond T. Management strategies in resection for hilar cholangiocarcinoma. Ann Surg. 1992; 215(1):31-8. [PubMed: 1309988]

41. Edge SB, Compton CC. The American Joint Committee on Cancer: the 7th edition of the AJCC cancer staging manual and the future of TNM. Ann Surg Oncol. 2010; 17(6):1471-4. [PubMed: 20180029]

42. Zervos EE, Osborne D, Goldin SB, et al. Stage does not predict survival after resection of hilar cholangiocarcinomas promoting an aggressive operative approach. Am J Surg. 2005; 190(5):8105. [PubMed: 16226963]

43. de Jong MC, Hong SM, Augustine MM, et al. Hilar cholangiocarcinoma: tumor depth as a predictor of outcome. Arch Surg. 2011; 146(6):697-703. [PubMed: 21690446]

44. Matsuo K, Rocha FG, Ito K, et al. The Blumgart preoperative staging system for hilar cholangiocarcinoma: analysis of resectability and outcomes in 380 patients. J Am Coll Surg. 2012; 215(3):343-55. [PubMed: 22749003]

45. Anderson CD, Pinson CW, Berlin J, et al. Diagnosis and treatment of cholangiocarcinoma. Oncologist. 2004; 9(1):43-57. [PubMed: 14755014]

46. Benson AB 3rd, Abrams TA, Ben-Josef E, et al. NCCN clinical practice guidelines in oncology: hepatobiliary cancers. J Natl Compr Canc Netw. 2009; 7(4):350-91. [PubMed: 19406039] 
47. Patel AH, Harnois DM, Klee GG, et al. The utility of CA 19-9 in the diagnoses of cholangiocarcinoma in patients without primary sclerosing cholangitis. Am J Gastroenterol. 2000; 95(1):204-7. [PubMed: 10638584]

48. Van Beers BE. Diagnosis of cholangiocarcinoma. HPB (Oxford). 2008; 10(2):87-93. [PubMed: 18773062]

49. Nehls O, Gregor M, Klump B. Serum and bile markers for cholangiocarcinoma. Semin Liver Dis. 2004; 24(2):139-54. [PubMed: 15192787]

50. Juntermanns B, Radunz S, Heuer M, et al. Tumor markers as a diagnostic key for hilar cholangiocarcinoma. Eur J Med Res. 2010; 15(8):357-61. [PubMed: 20947473]

51. Cha JH, Han JK, Kim TK, et al. Preoperative evaluation of Klatskin tumor: accuracy of spiral CT in determining vascular invasion as a sign of unresectability. Abdom Imaging. 2000; 25(5):500-7. [PubMed: 10931985]

52. Choi ER, Chung YH, Lee JK, et al. Preoperative evaluation of the longitudinal extent of borderline resectable hilar cholangiocarcinoma by intraductal ultrasonography. J Gastroenterol Hepatol. 2011; 26(12):1804-10. [PubMed: 21649729]

53. Aloia TA, Charnsangavej C, Faria S, et al. High-resolution computed tomography accurately predicts resectability in hilar cholangiocarcinoma. Am J Surg. 2007; 193(6):702-6. [PubMed: 17512280]

54. Watadani T, Akahane M, Yoshikawa T, et al. Preoperative assessment of hilar cholangiocarcinoma using multidetector-row CT: correlation with histopathological findings. Radiat Med. 2008; 26(7): 402-7. [PubMed: 18769997]

55. Chen HW, Lai EC, Pan AZ, et al. Preoperative assessment and staging of hilar cholangiocarcinoma with 16-multidetector computed tomography cholangiography and angiography. Hepatogastroenterology. 2009; 56(91-92):578-83. [PubMed: 19621658]

56. Akamatsu N, Sugawara Y, Osada H, et al. Diagnostic accuracy of multidetector-row computed tomography for hilar cholangiocarcinoma. J Gastroenterol Hepatol. 2010; 25(4):731-7. [PubMed: 20074166]

57. Choi JY, Kim MJ, Lee JM, et al. Hilar cholangiocarcinoma: role of preoperative imaging with sonography, MDCT, MRI, and direct cholangiography. AJR Am J Roentgenol. 2008; 191(5): 1448-57. [PubMed: 18941084]

58. Masselli G, Gualdi G. Hilar cholangiocarcinoma: MRI/MRCP in staging and treatment planning. Abdom Imaging. 2008; 33(4):444-51. [PubMed: 17638040]

59. Sai JK, Suyama M, Kubokawa Y, et al. Early detection of extrahepatic bile-duct carcinomas in the nonicteric stage by using MRCP followed by EUS. Gastrointest Endosc. 2009; 70(1):29-36. [PubMed: 19286177]

60. Holzknecht N, Gauger J, Sackmann M, et al. Breath-hold MR cholangiography with snapshot techniques: prospective comparison with endoscopic retrograde cholangiography. Radiology. 1998; 206(3):657-64. [PubMed: 9494483]

61. Yeh TS, Jan YY, Tseng JH, et al. Malignant perihilar biliary obstruction: magnetic resonance cholangiopancreatographic findings. Am J Gastroenterol. 2000; 95(2):432-40. [PubMed: 10685746]

62. Fulcher AS, Turner MA. HASTE MR cholangiography in the evaluation of hilar cholangiocarcinoma. AJR Am J Roentgenol. 1997; 169(6):1501-5. [PubMed: 9393153]

63. Silva MA, Tekin K, Aytekin F, et al. Surgery for hilar cholangiocarcinoma; a 10 year experience of a tertiary referral centre in the UK. Eur J Surg Oncol. 2005; 31(5):533-9. [PubMed: 15922889]

64. Park MS, Kim TK, Kim KW, et al. Differentiation of extrahepatic bile duct cholangiocarcinoma from benign stricture: findings at MRCP versus ERCP. Radiology. 2004; 233(1):234-40. [PubMed: 15333766]

65. Byrne MF, Gerke H, Mitchell RM, et al. Yield of endoscopic ultrasound-guided fine-needle aspiration of bile duct lesions. Endoscopy. 2004; 36(8):715-9. [PubMed: 15280978]

66. Lee JH, Salem R, Aslanian H, et al. Endoscopic ultrasound and fine-needle aspiration of unexplained bile duct strictures. Am J Gastroenterol. 2004; 99(6):1069-73. [PubMed: 15180727] 
67. Eloubeidi MA, Chen VK, Jhala NC, et al. Endoscopic ultrasound-guided fine needle aspiration biopsy of suspected cholangiocarcinoma. Clin Gastroenterol Hepatol. 2004; 2(3):209-13. [PubMed: 15017604]

68. Rauws EA, Kloek JJ, Gouma DJ, et al. Staging of cholangiocarcinoma: the role of endoscopy. HPB (Oxford). 2008; 10(2):110-2. [PubMed: 18773066]

69. Heimbach JK, Sanchez W, Rosen CB, et al. Trans-peritoneal fine needle aspiration biopsy of hilar cholangiocarcinoma is associated with disease dissemination. HPB (Oxford). 2011; 13(5):356-60. [PubMed: 21492336]

70. Cherqui D, Benoist S, Malassagne B, et al. Major liver resection for carcinoma in jaundiced patients without preoperative biliary drainage. Arch Surg. 2000; 135(3):302-8. [PubMed: 10722032]

71. Belghiti J, Hiramatsu K, Benoist S, et al. Seven hundred forty-seven hepatectomies in the 1990s: an update to evaluate the actual risk of liver resection. J Am Coll Surg. 2000; 191(1):38-46. [PubMed: 10898182]

72. Rerknimitr R, Angsuwatcharakon P, Ratanachu-ek T, et al. Asia-Pacific consensus recommendations for endoscopic and interventional management of hilar cholangiocarcinoma. $\mathrm{J}$ Gastroenterol Hepatol. 2013; 28(4):593-607. [PubMed: 23350673]

73. Liu F, Li Y, Wei Y, et al. Preoperative biliary drainage before resection for hilar cholangiocarcinoma: whether or not? A systematic review. Dig Dis Sci. 2011; 56(3):663-72. [PubMed: 20635143]

74. Tsai HM, Chuang CH, Lin XZ, et al. Factors relating to the short term effectiveness of percutaneous biliary drainage for hilar cholangiocarcinoma. World J Gastroenterol. 2009; 15(41): 5206-10. [PubMed: 19891021]

75. Grandadam S, Compagnon P, Arnaud A, et al. Role of preoperative optimization of the liver for resection in patients with hilar cholangiocarcinoma type III. Ann Surg Oncol. 2010; 17(12):315561. [PubMed: 20593243]

76. Farges O, Belghiti J, Kianmanesh R, et al. Portal vein embolization before right hepatectomy: prospective clinical trial. Ann Surg. 2003; 237(2):208-17. [PubMed: 12560779]

77. Abdalla EK, Barnett CC, Doherty D, et al. Extended hepatectomy in patients with hepatobiliary malignancies with and without preoperative portal vein embolization. Arch Surg. 2002; 137(6): 675-80. discussion 680-1. [PubMed: 12049538]

78. Hemming AW, Reed AI, Howard RJ, et al. Preoperative portal vein embolization for extended hepatectomy. Ann Surg. 2003; 237(5):686-91. discussion 691-3. [PubMed: 12724635]

79. van Lienden KP, van den Esschert JW, de Graaf W, et al. Portal vein embolization before liver resection: a systematic review. Cardiovasc Intervent Radiol. 2013; 36(1):25-34. [PubMed: 22806245]

80. Weiss MJ, Cosgrove D, Herman JM, et al. Multimodal treatment strategies for advanced hilar cholangiocarcinoma. Langenbecks Arch Surg. 2014; 399(6):679-92. [PubMed: 24962146]

81. Parikh AA, Abdalla EK, Vauthey JN. Operative considerations in resection of hilar cholangiocarcinoma. HPB (Oxford). 2005; 7(4):254-8. [PubMed: 18333202]

82. Connor S, Barron E, Wigmore SJ, et al. The utility of laparoscopic assessment in the preoperative staging of suspected hilar cholangiocarcinoma. J Gastrointest Surg. 2005; 9(4):476-80. [PubMed: 15797226]

83. Weber SM, DeMatteo RP, Fong Y, et al. Staging laparoscopy in patients with extrahepatic biliary carcinoma. Analysis of 100 patients. Ann Surg. 2002; 235(3):392-9. [PubMed: 11882761]

84. Barlow AD, Garcea G, Berry DP, et al. Staging laparoscopy for hilar cholangiocarcinoma in 100 patients. Langenbecks Arch Surg. 2013; 398(7):983-8. [PubMed: 23995711]

85. Lee SG, Song GW, Hwang S, et al. Surgical treatment of hilar cholangiocarcinoma in the new era: the Asan experience. J Hepatobiliary Pancreat Sci. 2010; 17(4):476-89. [PubMed: 19851704]

86. Nuzzo G, Giuliante F, Ardito F, et al. Improvement in perioperative and long-term outcome after surgical treatment of hilar cholangiocarcinoma: results of an Italian multicenter analysis of 440 patients. Arch Surg. 2012; 147(1):26-34. [PubMed: 22250108] 
87. Shimizu H, Kimura F, Yoshidome H, et al. Aggressive surgical resection for hilar cholangiocarcinoma of the left-side predominance: radicality and safety of left-sided hepatectomy. Ann Surg. 2010; 251(2):281-6. [PubMed: 20054275]

88. Unno M, Katayose Y, Rikiyama T, et al. Major hepatectomy for perihilar cholangiocarcinoma. J Hepatobiliary Pancreat Sci. 2010; 17(4):463-9. [PubMed: 19941010]

89. Regimbeau JM, Fuks D, Pessaux P, et al. Tumour size over $3 \mathrm{~cm}$ predicts poor short-term outcomes after major liver resection for hilar cholangiocarcinoma. By the HC-AFC-2009 group. HPB (Oxford). 2015; 17(1):79-86. [PubMed: 24992279]

90. Zheng-Rong L, Hai-Bo Y, Xin C, et al. Resection and drainage of hilar cholangiocarcinoma: an 11year experience of a single center in mainland China. Am Surg. 2011; 77(5):627-33. [PubMed: 21679599]

91. Shi Z, Yang MZ, He QL, et al. Addition of hepatectomy decreases liver recurrence and leads to long survival in hilar cholangiocarcinoma. World J Gastroenterol. 2009; 15(15):1892-6. [PubMed: 19370789]

92. Ito F, Agni R, Rettammel RJ, et al. Resection of hilar cholangiocarcinoma: concomitant liver resection decreases hepatic recurrence. Ann Surg. 2008; 248(2):273-9. [PubMed: 18650638]

93. Dinant S, Gerhards MF, Busch OR, et al. The importance of complete excision of the caudate lobe in resection of hilar cholangiocarcinoma. HPB (Oxford). 2005; 7(4):263-7. [PubMed: 18333204]

94. Kow AW, Wook CD, Song SC, et al. Role of caudate lobectomy in type III A and III B hilar cholangiocarcinoma: a 15-year experience in a tertiary institution. World J Surg. 2012; 36(5): 1112-21. [PubMed: 22374541]

95. Cheng QB, Yi B, Wang JH, et al. Resection with total caudate lobectomy confers survival benefit in hilar cholangiocarcinoma of Bismuth type III and IV. Eur J Surg Oncol. 2012; 38(12):1197-203. [PubMed: 22992326]

96. Wu XS, Dong P, Gu J, et al. Combined portal vein resection for hilar cholangiocarcinoma: a metaanalysis of comparative studies. J Gastrointest Surg. 2013; 17(6):1107-15. [PubMed: 23592188]

97. de Jong MC, Marques H, Clary BM, et al. The impact of portal vein resection on outcomes for hilar cholangiocarcinoma: a multi-institutional analysis of 305 cases. Cancer. 2012; 118(19):473747. [PubMed: 22415526]

98. Abbas S, Sandroussi C. Systematic review and meta-analysis of the role of vascular resection in the treatment of hilar cholangiocarcinoma. HPB (Oxford). 2013; 15(7):492-503. [PubMed: 23750491]

99. Miyazaki M, Kato A, Ito H, et al. Combined vascular resection in operative resection for hilar cholangiocarcinoma: does it work or not? Surgery. 2007; 141(5):581-8. [PubMed: 17462457]

100. Cheng Q, Luo X, Zhang B, et al. Predictive factors for prognosis of hilar cholangiocarcinoma: postresection radiotherapy improves survival. Eur J Surg Oncol. 2007; 33(2):202-7. [PubMed: 17088040]

101. Song SC, Choi DW, Kow AW, et al. Surgical outcomes of 230 resected hilar cholangiocarcinoma in a single centre. ANZ J Surg. 2013; 83(4):268-74. [PubMed: 22943422]

102. Su CH, Tsay SH, Wu CC, et al. Factors influencing postoperative morbidity, mortality, and survival after resection for hilar cholangiocarcinoma. Ann Surg. 1996; 223(4):384-94. [PubMed: 8633917]

103. Abdel Wahab M, Fathy O, Elghwalby N, et al. Resectability and prognostic factors after resection of hilar cholangiocarcinoma. Hepatogastroenterology. 2006; 53(67):5-10. [PubMed: 16506367]

104. Shimoda M, Farmer DG, Colquhoun SD, et al. Liver transplantation for cholangiocellular carcinoma: analysis of a single-center experience and review of the literature. Liver Transpl. 2001; 7(12):1023-33. [PubMed: 11753904]

105. Meyer CG, Penn I, James L. Liver transplantation for cholangiocarcinoma: results in 207 patients. Transplantation. 2000; 69(8):1633-7. [PubMed: 10836374]

106. Rosen CB, Heimbach JK, Gores GJ. Liver transplantation for cholangiocarcinoma. Transpl Int. 2010; 23(7):692-7. [PubMed: 20497401]

107. Heimbach JK, Haddock MG, Alberts SR, et al. Transplantation for hilar cholangiocarcinoma. Liver Transpl. 2004; 10(10 Suppl 2):S65-8. [PubMed: 15382214] 
108. Rea DJ, Heimbach JK, Rosen CB, et al. Liver transplantation with neoadjuvant chemoradiation is more effective than resection for hilar cholangiocarcinoma. Ann Surg. 2005; 242(3):451-8. discussion 458-61. [PubMed: 16135931]

109. Rosen CB, Heimbach JK, Gores GJ. Surgery for cholangiocarcinoma: the role of liver transplantation. HPB (Oxford). 2008; 10(3):186-9. [PubMed: 18773052]

110. Nakeeb A, Pitt HA. Radiation therapy, chemotherapy and chemoradiation in hilar cholangiocarcinoma. HPB (Oxford). 2005; 7(4):278-82. [PubMed: 18333207]

111. Valle JW, Wasan H, Johnson P, et al. Gemcitabine alone or in combination with cisplatin in patients with advanced or metastatic cholangiocarcinomas or other biliary tract tumours: a multicentre randomised phase II study — the UK ABC-01 Study. Br J Cancer. 2009; 101(4):6217. [PubMed: 19672264]

112. Todoroki T. Chemotherapy for bile duct carcinoma in the light of adjuvant chemotherapy to surgery. Hepatogastroenterology. 2000; 47(33):644-9. [PubMed: 10919004]

113. Patt YZ, Jones DV Jr, Hoque A, et al. Phase II trial of intravenous flourouracil and subcutaneous interferon alfa-2b for biliary tract cancer. J Clin Oncol. 1996; 14(8):2311-5. [PubMed: 8708722]

114. Lee MA, Woo IS, Kang JH, et al. Epirubicin, cisplatin, and protracted infusion of 5-FU (ECF) in advanced intrahepatic cholangiocarcinoma. J Cancer Res Clin Oncol. 2004; 130(6):346-50. [PubMed: 14997381]

115. Thongprasert S. The role of chemotherapy in cholangiocarcinoma. Ann Oncol. 2005; 16(2):ii936. [PubMed: 15958484]

116. Murakami Y, Uemura K, Sudo T, et al. Gemcitabine-based adjuvant chemotherapy improves survival after aggressive surgery for hilar cholangiocarcinoma. J Gastrointest Surg. 2009; 13(8): 1470-9. [PubMed: 19421824]

117. El-Khoueiry AB, Rankin C, Siegel AB, et al. S0941: a phase 2 SWOG study of sorafenib and erlotinib in patients with advanced gallbladder carcinoma or cholangiocarcinoma. Br J Cancer. 2014; 110(4):882-7. [PubMed: 24423918]

118. El-Khoueiry AB, Rankin CJ, Ben-Josef E, et al. SWOG 0514: a phase II study of sorafenib in patients with unresectable or metastatic gallbladder carcinoma and cholangiocarcinoma. Invest New Drugs. 2012; 30(4):1646-51. [PubMed: 21748296]

119. Lubner SJ, Mahoney MR, Kolesar JL, et al. Report of a multicenter phase II trial testing a combination of biweekly bevacizumab and daily erlotinib in patients with unresectable biliary cancer: a phase II Consortium study. J Clin Oncol. 2010; 28(21):3491-7. [PubMed: 20530271]

120. Pitt HA, Nakeeb A, Abrams RA, et al. Perihilar cholangiocarcinoma. Postoperative radiotherapy does not improve survival. Ann Surg. 1995; 221(6):788-97. discussion 797-8. [PubMed: 7794082]

121. Sagawa N, Kondo S, Morikawa T, et al. Effectiveness of radiation therapy after surgery for hilar cholangiocarcinoma. Surg Today. 2005; 35(7):548-52. [PubMed: 15976951]

122. Gerhards MF, van Gulik TM, Gonzalez Gonzalez D, et al. Results of postoperative radiotherapy for resectable hilar cholangiocarcinoma. World J Surg. 2003; 27(2):173-9. [PubMed: 12616432]

123. Todoroki T, Ohara K, Kawamoto T, et al. Benefits of adjuvant radiotherapy after radical resection of locally advanced main hepatic duct carcinoma. Int J Radiat Oncol Biol Phys. 2000; 46(3):5817. [PubMed: 10701737]

124. Wang Y, Yang H, Shen C, et al. Surgical procedure and long-term survival of hilar cholangiocarcinoma. Int J Clin Exp Med. 2015; 8(1):1122-8. [PubMed: 25785102]

125. Higuchi R, Ota T, Yazawa T, et al. Improved surgical outcomes for hilar cholangiocarcinoma: changes in surgical procedures and related outcomes based on 40 years of experience at a single institution. Surg Today. 201510.1007/s00595-015-1119-1

126. Furusawa N, Kobayashi A, Yokoyama T, et al. Surgical treatment of 144 cases of hilar cholangiocarcinoma without liver-related mortality. World J Surg. 2014; 38(5):1164-76. [PubMed: 24305942]

127. Nagino M, Ebata T, Yokoyama Y, et al. Evolution of surgical treatment for perihilar cholangiocarcinoma: a single-center 34-year review of 574 consecutive resections. Ann Surg. 2013; 258(1):129-40. [PubMed: 23059502] 
128. Cannon RM, Brock G, Buell JF. Surgical resection for hilar cholangiocarcinoma: experience improves resectability. HPB (Oxford). 2012; 14(2):142-9. [PubMed: 22221577] 


\section{a}
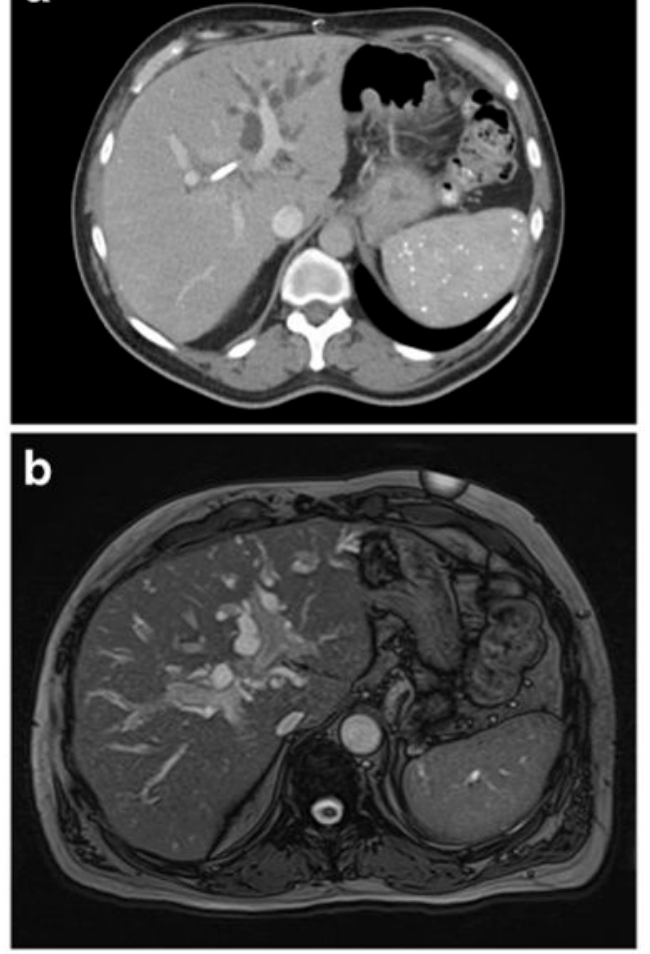

Fig. 1. Abdominal CT scan (a) and MRI (b) demonstrating left biliary tree dilatation in a 63year-old male with hilar cholangiocarcinoma 


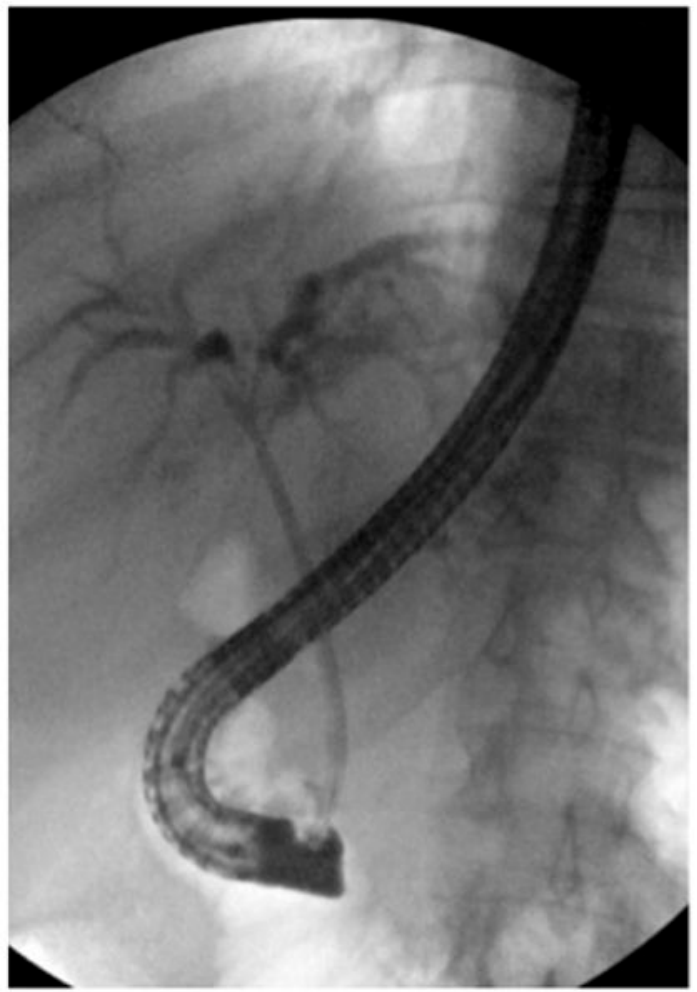

Fig. 2. ERCP demonstrating mild left and right biliary tree dilatation with non-opacification of the common bile duct due to the presence of a hilar cholangiocarcinoma in a 56-year-old male, prior to stent placement 


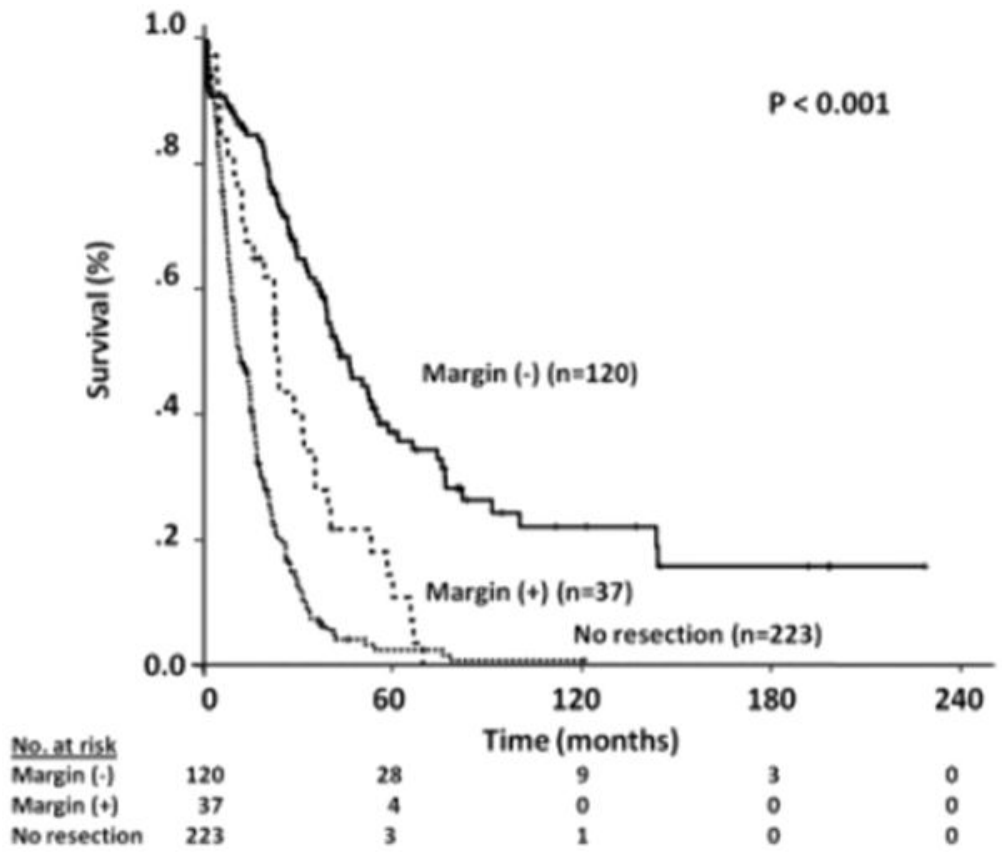

Fig. 3. Kaplan-Meier Survival for hilar cholangiocarcinoma based upon resection margin (Reprinted from Matsuo ${ }^{44}$ ) 
Table 1

Selected recent case series involving surgical resection of more than one hundred hilar cholangiocarcinoma

\begin{tabular}{|c|c|c|c|}
\hline Author & Year of publication & Number of patients & Overall 5-year survival \\
\hline \multirow[t]{2}{*}{ Wang $^{124}$} & 2015 & 204 & $23.7 \%$ (radical resection) \\
\hline & & & $4.5 \%$ (palliative resection) \\
\hline \multirow[t]{3}{*}{ Higuchi $^{125}$} & 2015 & 239 & $9.3 \%(1974-1988)$ \\
\hline & & & $41.1 \%(1989-2003)$ \\
\hline & & & $55.6 \%(2004-2008)$ \\
\hline Regimbeau $^{89}$ & 2015 & 331 & $53 \%$ \\
\hline \multirow[t]{2}{*}{ Furusawa $^{126}$} & 2014 & 144 & $33 \%(1990-2000)$ \\
\hline & & & $35 \%(2001-2012)$ \\
\hline Nagino $^{127}$ & 2013 & 574 & $32.5 \%$ \\
\hline $\mathrm{Cho}^{10}$ & 2012 & 105 & $34.1 \%$ \\
\hline Cannon $^{128}$ & 2012 & 110 & $17.7 \%$ \\
\hline Matsuo $^{44}$ & 2012 & 157 & $37.5 \%$ \\
\hline Song ${ }^{101}$ & 2012 & 230 & $33 \%$ \\
\hline De Jong ${ }^{97}$ & 2012 & 305 & $20.2 \%$ \\
\hline Nuzzo $^{86}$ & 2012 & 440 & $25.5 \%$ \\
\hline $\mathrm{Lee}^{85}$ & 2010 & 302 & $32.5 \%$ \\
\hline \multirow[t]{2}{*}{ Shimizu $^{87}$} & 2010 & 224 & $28.3 \%$ (left hepatectomy) \\
\hline & & & $30.3 \%$ (right hepatectomy) \\
\hline Unno $^{88}$ & 2010 & 125 & $34.7 \%$ \\
\hline
\end{tabular}

